\title{
Comparison of Plasma Concentrations for Some Biological Markers in Patients with Type 2 Diabetes Before and After Consuming a Vegetarian Diet
}

\author{
Hala H Deeb Racha K Bachour \\ Faculty of Pharmacy, Al Hawash Private University
}

\begin{abstract}
Background: The prevalence of diabetes mellitus has been increasing worldwide in recent years. Long-term diabetes results in vascular changes and dysfunction. Complications of diabetes are the major causes of morbidity and mortality in diabetic patients. ${ }^{[1]}$ Renal involvement is an important complication of diabetes mellitus. Endstage kidney with renal failure accounts for deaths in more than $10 \%$ of all diabetics. ${ }^{[2]}$

Diet therapy is fundamentally important for both diabetes and diabetic kidney disease (DKD) to maintain glucose control and suppress the progression of renal damage. ${ }^{[3]}$ The main nutrition-related goals for people with chronic kidney disease (CKD) involve the slowing of kidney failure progression rate and minimizing uremic toxicity and metabolic disorders of kidney failure, diminishing proteinuria, maintaining good nutritional status, and lowering the risk of secondary complications including cardiovascular disease, bone disease, and disturbed blood pressure control ${ }^{[4]}$.

The aim of our study was to compare some biological markers in patients with type 2 diabetes whom are at risk of developing kidney failure, before and after starting a vegetarian diet for at least 30 days.

Materials \& Methods: In this study we measured plasma concentrations of Urea, Creatinine, Fasting Glucose, and calculated EGFR according to Cockcroft-Gault equation for of 20 patients with type 2 diabetes (5 males, 15 females), with an average age of 63 years. Blood-sampling and testing was conducted in two time periods. The first one was at the regular diet for subjects consuming all kind of foods including proteins of animal and plant sources, the second one was after at least 30 days of fasting involves abstention from all animal products (Easter Fasting).

Results: Plasma Urea was significantly lower after the diet (mean \pm SD: $27 \pm 11 \mathrm{mg} / \mathrm{dl}$ ) than before diet (mean \pm $\mathrm{SD}: 42 \pm 23.55 \mathrm{mg} / \mathrm{dl})$. Using student's t-test $\mathrm{P}$ was: $0.001<0.05$. Plasma Creatinine was significantly lower after the diet (mean $\pm \mathrm{SD}: 1.09 \pm 0.25 \mathrm{mg} / \mathrm{dl})$ than before diet (mean $\pm \mathrm{SD}: 1.2 \pm 0.3 \mathrm{mg} / \mathrm{dl})$. Using student's t-test $\mathrm{P}$ was: $0.022<0.05$. Plasma Glucose was lower after the diet (mean \pm SD: $126 \pm 52.15 \mathrm{mg} / \mathrm{dl}$ ) than before diet (mean $\pm \mathrm{SD}: 140 \pm 67.44 \mathrm{mg} / \mathrm{dl}$ ). Using student's t-test $\mathrm{P}$ was: $0.108>0.05$. EGFR was higher after the diet (mean $\pm \mathrm{SD}$ : $71.45 \pm 26.2 \mathrm{ml} / \mathrm{min}$ ) than before diet (mean $\pm \mathrm{SD}: 69.45 \pm 25.54 \mathrm{ml} / \mathrm{min})$. Using student's t-test P was: $0.039<$ 0.05 .

Conclusion: These results may indicate that the vegetarian diet could be a kidney protective for patients with type 2 diabetes.
\end{abstract}

DOI: $10.7176 / \mathrm{CMR} / 11-6-04$

Publication date: August 31st 2019

Theoretical Brief

Diabetes mellitus:

$\mathrm{DM}$ is a metabolic disorder characterized by hyperglycemia resulting from defects in insulin secretion, insulin action, or both. ${ }^{[5]}$

Type 1 diabetes: a result of cellular-mediated autoimmune destruction of the $\beta$ cells of the pancreas, causing an absolute deficiency of insulin secretion. It constitutes only $10 \%$ to $20 \%$ of all cases of diabetes and commonly occurs in childhood and adolescence. Characteristics include abrupt onset, insulin dependence, and ketosis tendency. This diabetic type is genetically related. ${ }^{[5]}$

Type 2 diabetes: as a result of an individual's resistance to insulin with an insulin secretory defect. It constitutes about $80 \%$ of the diabetes cases. Characteristics usually include adult onset of the disease and milder symptoms than in type 1, with ketoacidosis seldom occurring. However, these patients are at an increased risk of developing macrovascular and microvascular complications. ${ }^{[5]}$

\section{Complications of Diabetes:}

Complications are broadly divided into 2 major groups:

I. Acute metabolic complications: These include diabetic ketoacidosis, hyperosmolar nonketotic coma, and hypoglycemia.

II. Late systemic complications: These are atherosclerosis, diabetic microangiopathy, diabetic nephropathy, diabetic neuropathy, diabetic retinopathy and infections. (Fig 1) ${ }^{[2]}$ 


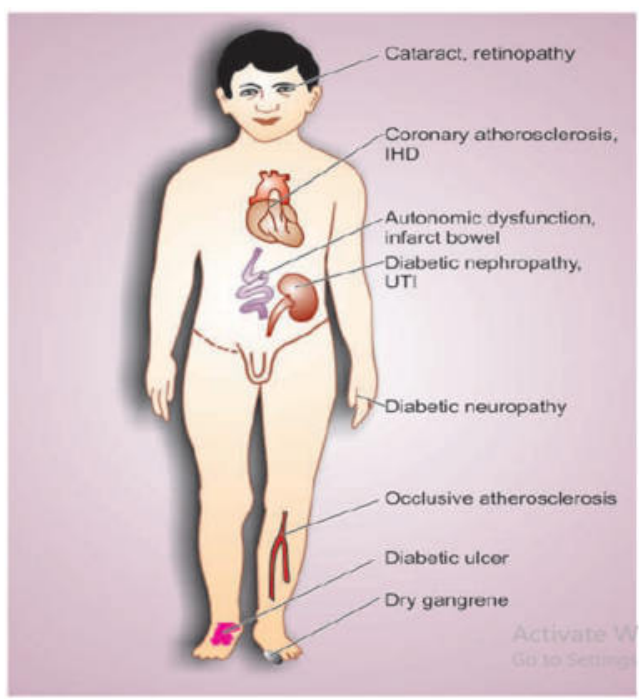

Figure1: Late Systemic Complications

\section{Pathogenesis of Complications:}

The following biochemical mechanisms have been proposed to explain the development of complications of diabetes mellitus (Fig 2):

1. Non-enzymatic protein glycosylation: The free amino group of various body proteins binds by non-enzymatic mechanism to glucose; this process is called glycosylation. Accumulation of reversible glycosylation products on collagen and other tissues of the blood vessel wall which subsequently become stable and irreversible and form advanced glycosylation end-products (AGE), and cause the basement membrane in the vessel wall to grow abnormally thicker and weaker. Therefore they bleed, leak protein, and slow the flow of blood through the body. As a result, some organs and tissues do not get enough blood. ${ }^{[2]}$

2. Polyol (Sorbitol) pathway mechanism: This mechanism is responsible for producing lesions in the lens of the eye, kidney and peripheral nerves. These tissues have decreased activity of sorbitol dehydrogenase which leads to sorbitol accumulation results in entry of water inside the cell and consequent cellular swelling and cell damage. ${ }^{[2]}$

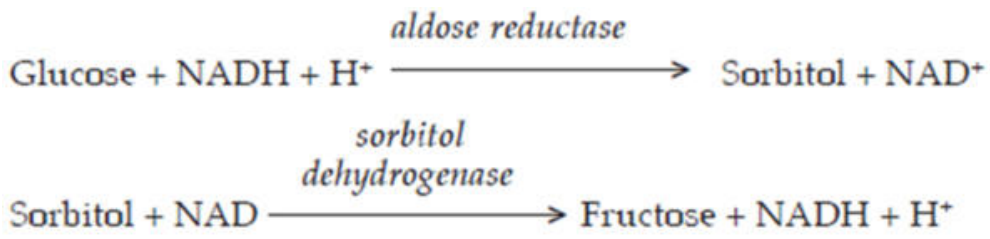

3. Excessive oxygen free radicals: In hyperglycaemia, there is increased production of reactive oxygen free radicals from mitochondrial oxidative phosphorylation which may damage various target cells in diabetes. ${ }^{[2]}$ 

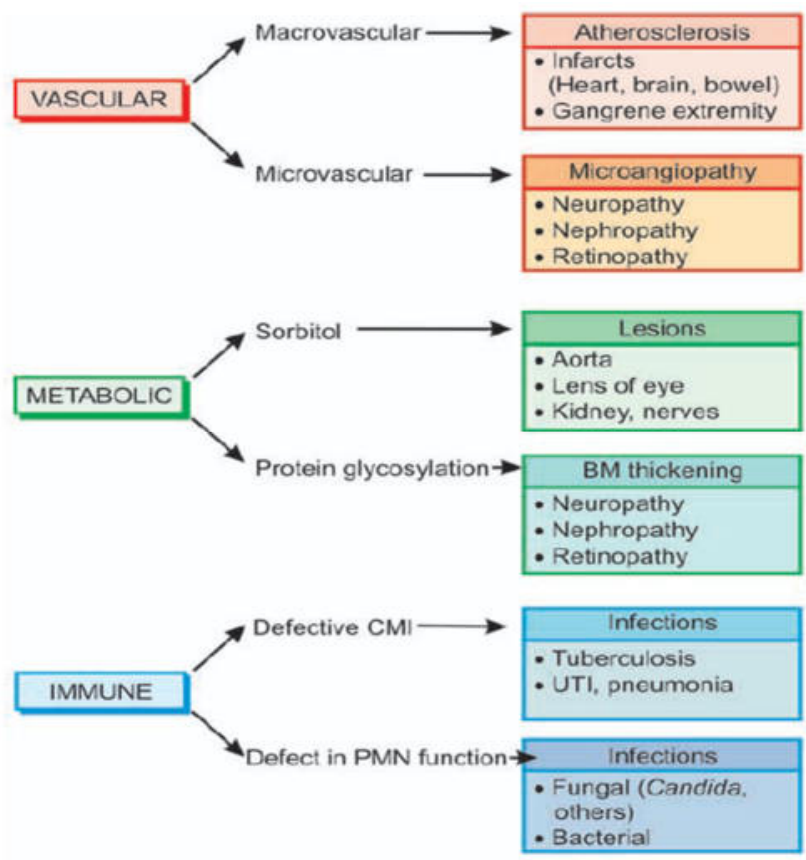

Figure 2: Biochemical Mechanisms of Diabetes Complications

\section{Diabetic Nephropathy}

Renal involvement is an important complication of diabetes mellitus. A variety of clinical syndromes is associated with diabetic nephropathy that includes asymptomatic proteinuria, nephrotic syndrome, progressive renal failure and hypertension. ${ }^{[2]}$ Diabetic nephropathy encompasses 4 types of renal lesions in diabetes mellitus: diabetic glomerulosclerosis, vascular lesions, diabetic pyelonephritis and tubular lesions (Armanni-Ebstein lesions). ${ }^{[2]}$

\section{Practical Part}

Materials \& Methods:

Subjects: Our study included 20 subjects of Type 2 Diabetes patients (average age 63 years; 5 men, 15 women) who have been diagnosed with diabetes for at least one year.

Laboratory measurements: Blood sampling was performed after all night fasting in two time periods; The first one was at the regular diet for subjects consuming all kind of foods including proteins of animal and plant sources, the second one was after at least 30 days of fasting involves abstention from all animal products. Samples were put in Heparin tubes, centrifuged (2000 rpm, $10 \mathrm{~min}$ ). Serum Urea, Creatinine, and Glucose, were measured using standard methods (BioSystems Reagents) in the routine clinical laboratory at Al Hawash Private University. Blood pressure (BP), weight ( $\mathrm{kg}$ ) measurements, and nutritional Information were taken for all patients. Statistical analysis: Values are reported as mean \pm SD. Comparisons between results before and after fasting were made by Student's t-test. Calculations were performed using a standard statistical package (Microsoft office excel 2003). 


\section{Results}

1- Plasma Urea was significantly lower after the diet (mean \pm SD: $27 \pm 11 \mathrm{mg} / \mathrm{dl}$ ) than before diet (mean \pm SD: $42 \pm 23.55 \mathrm{mg} / \mathrm{dl}) .(\mathrm{P}=0.001<0.05)$. (Fig 3)

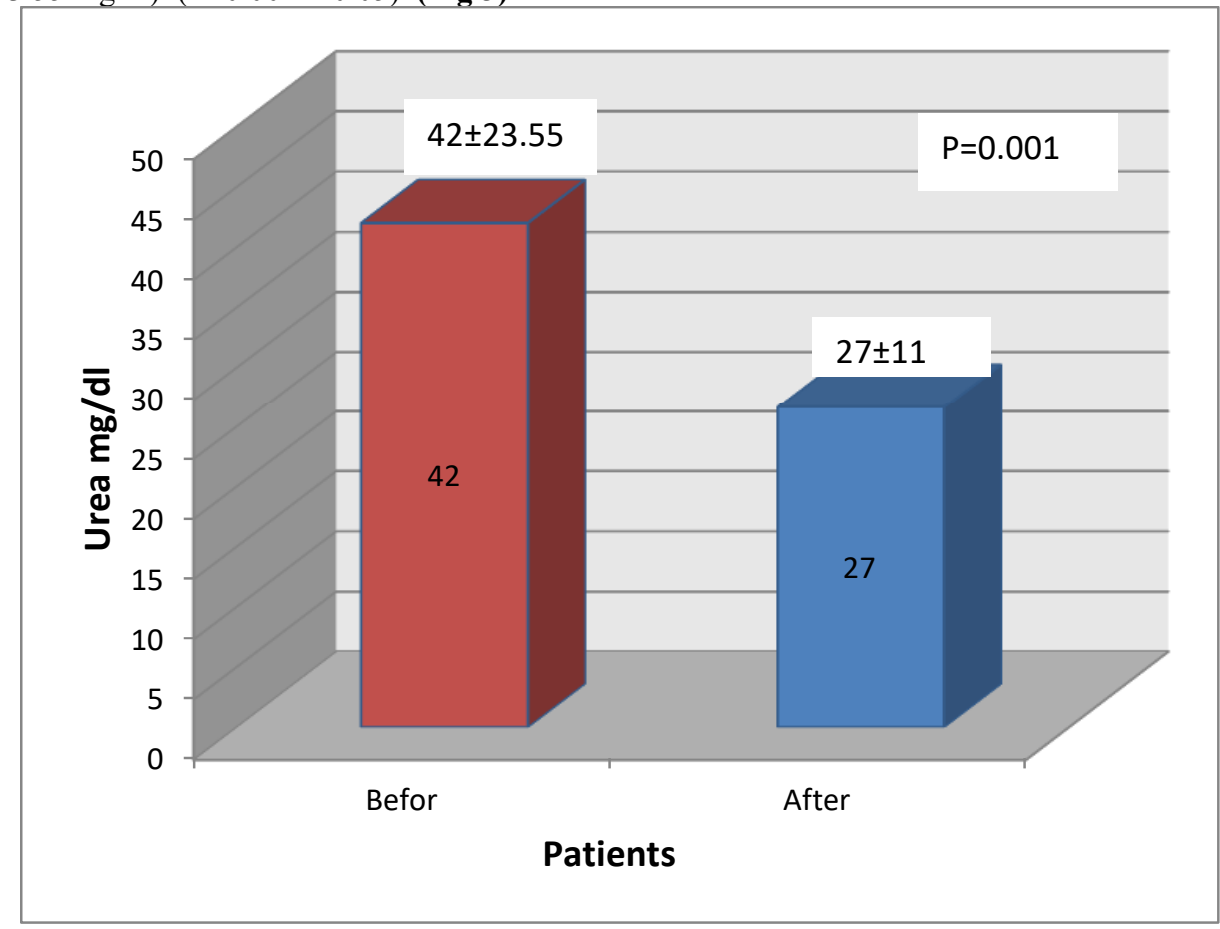

Figure 3

2- Plasma Creatinine was lower after the diet (mean \pm SD: $1.09 \pm 0.25 \mathrm{mg} / \mathrm{dl})$ than before $\operatorname{diet}(\mathrm{mean} \pm \mathrm{SD}: 1.2$ $\pm 0.3 \mathrm{mg} / \mathrm{dl})$. $(\mathrm{P}=0.022<0.05)$. (Fig 4)

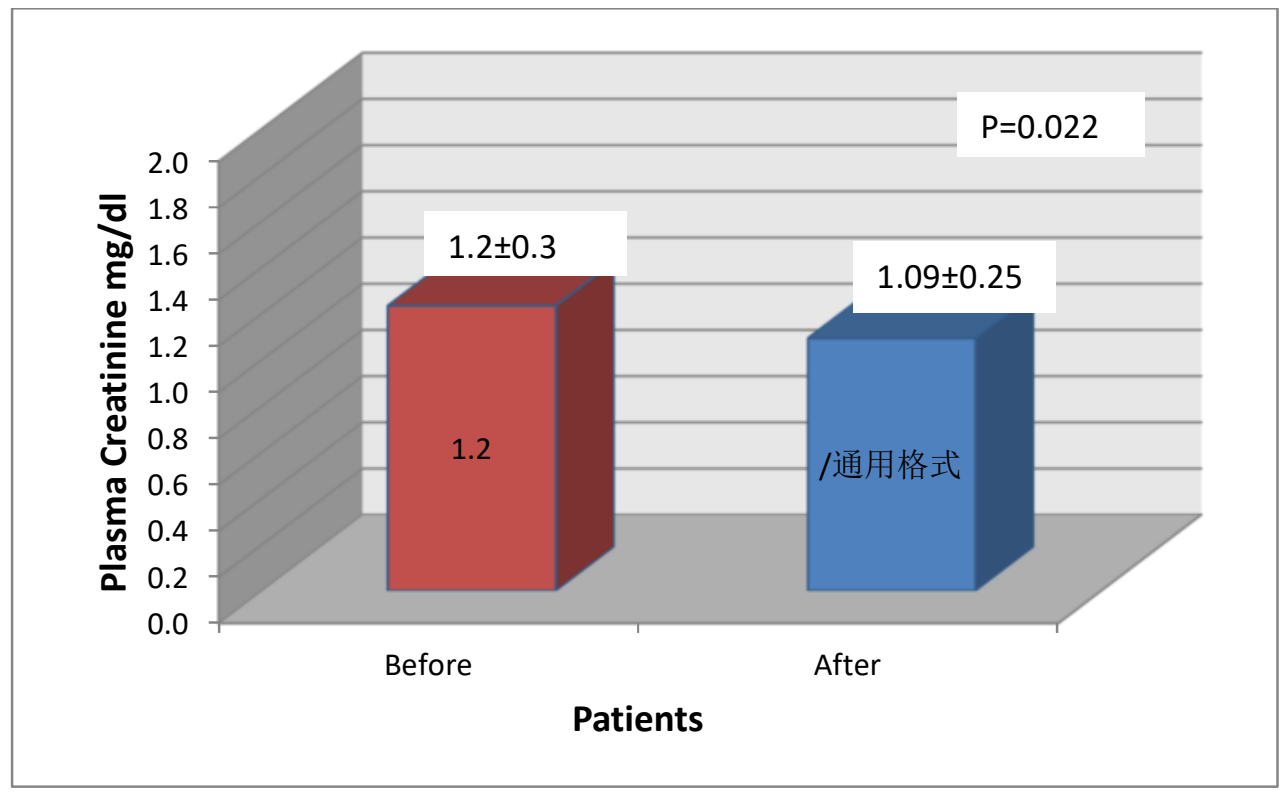

Figure 4 
3- Plasma Glucose was lower after the diet (mean \pm SD: $126 \pm 52.15 \mathrm{mg} / \mathrm{dl}$ ) than before diet (mean \pm SD: $140 \pm$ $67.44 \mathrm{mg} / \mathrm{dl}) .(\mathrm{P}=0.108>0.05)$. (Fig 5)

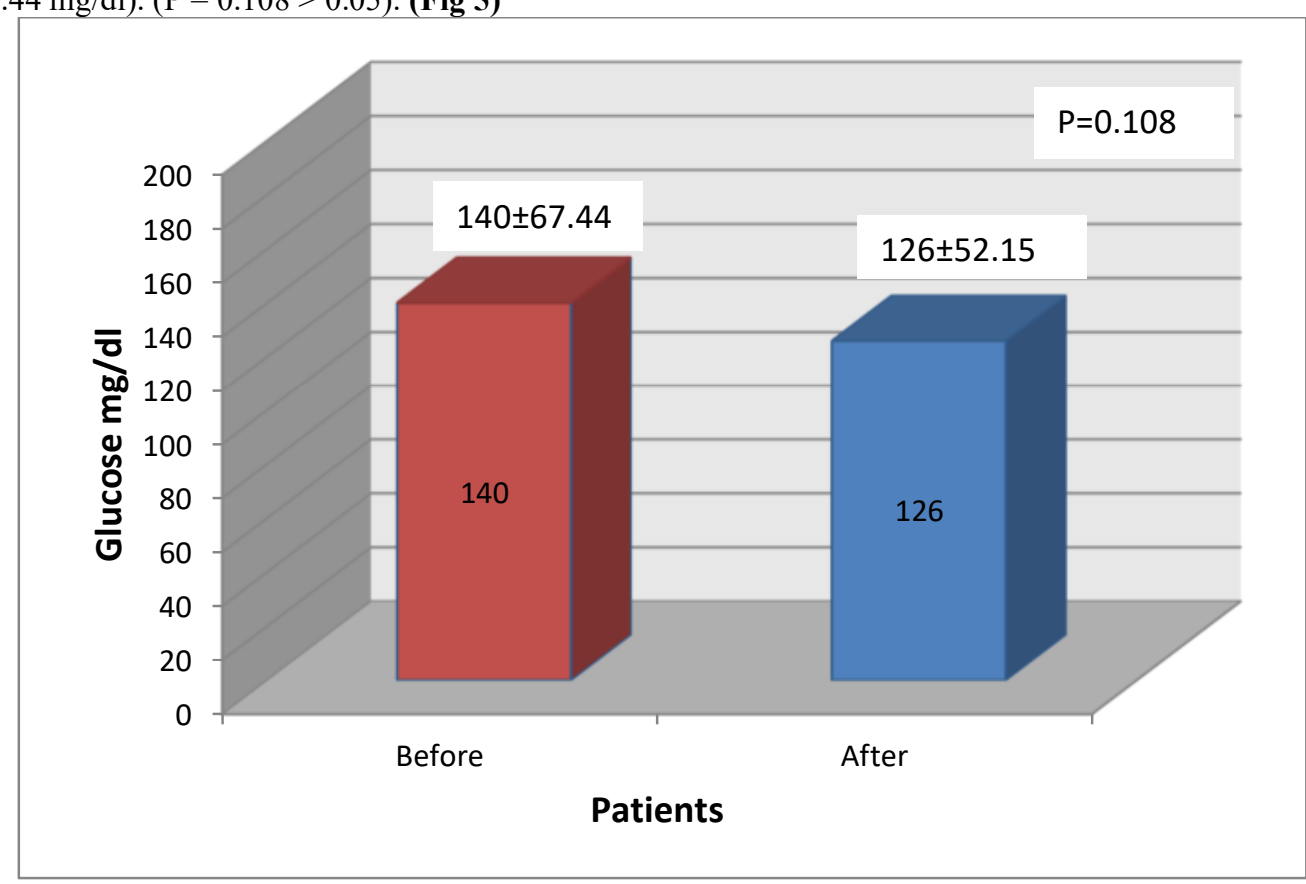

Figure 5

4- EGFR was higher after the diet (mean \pm SD: $71.45 \pm 26.2 \mathrm{ml} / \mathrm{min}$ ) than before diet (mean \pm SD: $69.45 \pm 25.54$ $\mathrm{ml} / \mathrm{min})$. $(\mathrm{P}=0.039<0.05)$. (Fig 6)

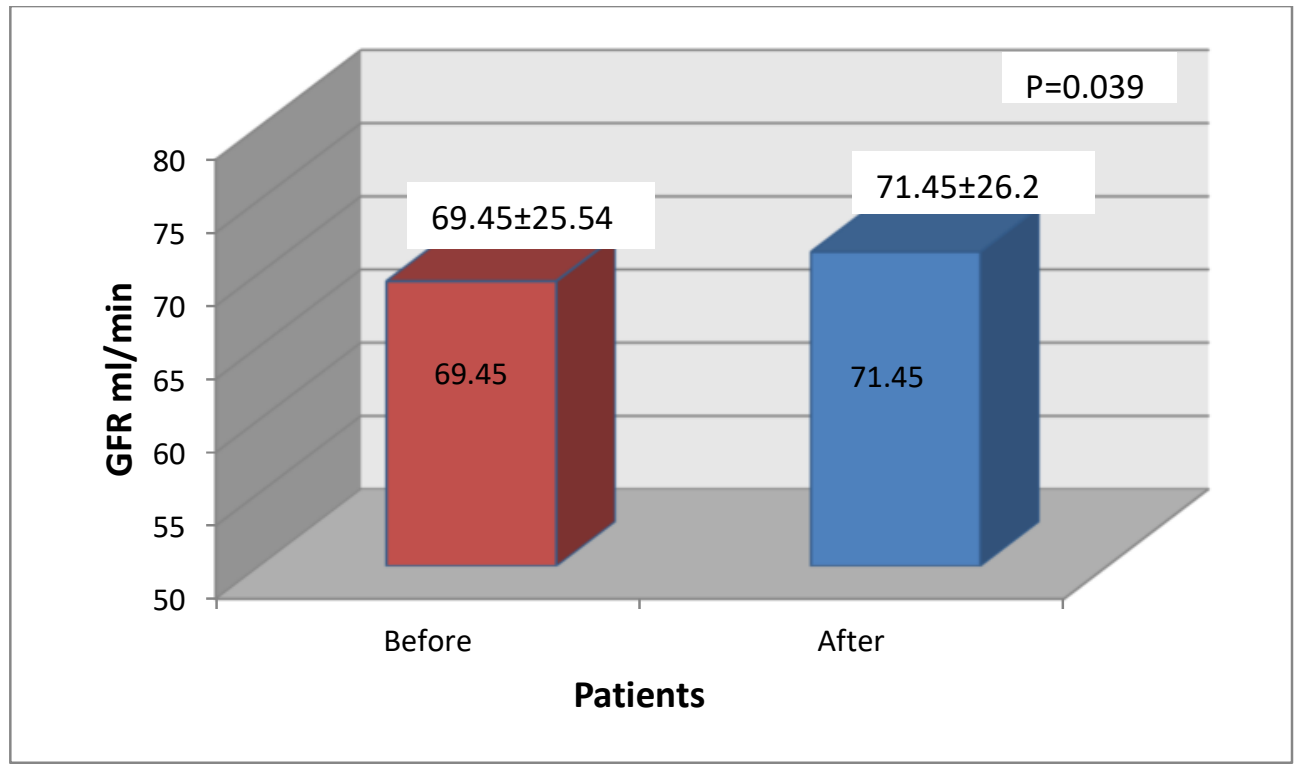

Figure 6

\section{Discussion}

According to our results we noticed a statistically considered decrease in Urea and Creatinine concentrations after the vegetarian diet and a statistically considered increase in GFR after the vegetarian diet.

We also noticed a decrease in Fasting Glucose concentrations after the vegetarian diet but it was not statistically considered.

The outcome of the influence of diet on patients with chronic kidney disease has been widely studied. For decades, vegetarianism and kidney disease have been thought to be impossible to combine. The results of narrow 
studies suggest that a plant-based diet can delay the progression of CKD, protect endothelium, help to control high blood pressure, and decrease proteinuria. ${ }^{[6]}$

Animal protein intake profoundly ${ }^{[7]}$ affects normal human kidney function, inducing what is called hyperfiltration, which increases the workload of the kidney. This may help explain why our kidneys fail so often. [8]

We saw in a study that eating meat increases the workload on the kidneys within hours of consumption. [9]

Why does animal protein cause that overload reaction, but plant protein doesn't? The renal reaction appears to be an inflammatory response triggered by the animal protein. ${ }^{10]}$

The consumption of animal fat can actually alter the structure of the kidney, and animal protein can deliver an acid load to the kidneys, increase ammonia production, and damage the sensitive kidney cells. This is why restricting protein intake is recommended for preventing kidney function decline. ${ }^{[11]}$

As for glycemic control in diabetic patients, many studies indicate that replacing sources of animal with plant protein leads to modest improvements in glycemic control in individuals with diabetes. There was a significant improvement in fasting glucose, as well as HbA1c in individuals with T2D. ${ }^{[12]}\left[{ }^{[13]}\left[{ }^{14]}\right.\right.$

\section{Conclusion}

Our results may indicate that the vegetarian diet could be a kidney protective for patients with type 2 diabetes, and could be of benefit for controlling blood sugar in diabetic patients.

Owing to uncertainties in our analyses there is a need for larger, longer, higher quality studies that includes more analytical tests (Urea Creatinine, Microalbuminuria, Electrolytes, Lipids), and comparison with healthy control groups with no evidence of having diabetes or kidney disease.

\section{References}

1- Adler A.I., Stevens R.J., Manley S.E., Bilous R.W., Cull C.A., Holman R.R., Ukpds G. Development and progression of nephropathy in type 2 diabetes: The United Kingdom Prospective Diabetes Study (UKPDS 64) Kidney Int. 2003;63:225-232.

2- Harsh Mohan .,Textbook of Pathology

3- American Diabetes Association Standards of medical care in diabetes-2018 abridged for primary care providers. Clin. Diabetes. 2018; 36: 14-37.

4- Renal Dietitians Dietetic Practice Group. National Kidney Foundation Council on Renal Nutrition. National Renal Diet: Professional Guide. 2nd ed. The American Dietetic Association; Chicago, IL, USA: 2002.

5- Bishop M.L., Fody E.P ., Schoeff L., Clinical Chemistry principles, procedures, correlations. Fifth edition. Lippincott Williams \&Wilkins.

6- Azadbakht L., Atabak S., Esmaillzadek A. Soy protein intake, cardiorenal indices, and $\backslash \mathrm{C}$ reactive protein in type II diabetes with nephropathy; a longitudinal randomized clinical trial. Diabetes Care. 2008; 31:648-654.

7- Kontessis P., Jones S., Dodds R., Trevisan R., Nosadini R., Fioretto P., Borsato M., Sacerdoti D., Viberti G. Renal, metabolic and hormonal responses to ingestions of animal and vegetable proteins. Kidney Int. 1990; 8:136-144.

8- Soroka N1, Silverberg DS, Greemland M, Birk Y, Blum M, Peer G, Iaina A. Comparison of a vegetable-based (soya) and an animal-based low-protein diet in predialysis chronic renal failure patients.

9- Brenner BM, Meyer TW, Hostetter TH. Dietary protein intake and the progressive nature of kidney disease: the role of hemodynamically mediated glomerular injury in the pathogenesis of progressive glomerular sclerosis in aging, renal ablation, and intrinsic renal disease.

10- Kontessis P1, Jones S, Dodds R, Trevisan R, Nosadini R, Fioretto P, Borsato M, Sacerdoti D, Viberti G. Renal, metabolic and hormonal responses to ingestion of animal and vegetable proteins.

11- Fioretto P1, Trevisan R, Valerio A, Avogaro A, Borsato M, Doria A, Semplicini A, Sacerdoti D, Jones S, Bognetti E, et al. Impaired renal response to a meat meal in insulin-dependent diabetes: role of glucagon and prostaglandins.

12- Odermatt A1. The Western-style diet: a major risk factor for impaired kidney function and chronic kidney disease.

13- Viguiliouk E., Kendall C.W., Blanco Mejia S., Cozma A.I., Ha V., Mirrahimi A., Jayalath V.H., Augustin L.S., Chiavaroli L., Leiter L.A., et al. Effect of tree nuts on glycemic control in diabetes: A systematic review and meta-analysis of randomized controlled dietary trials. PLoS ONE. 2014; 9:e103376.

14- Effie Viguiliouk,1,2 Sarah E. Stewart,1,2 Viranda H. Jayalath,1,3,4 Alena Praneet Ng,1 Arash Mirrahimi,1,5 Russell J. de Souza,1,2,6 Anthony J. Hanley,2,7,8,9 Richard P. Bazinet,2 Sonia Blanco Mejia,1,2 Lawrence A. Leiter,1,2,8,10,11 Robert G. Josse,1,2,8,10,11 Cyril W.C. Kendall,1,2,12 David J.A. Jenkins,1,2,8,10,11 and John L. Sievenpiper1,2,10,11. Effect of Replacing Animal Protein with Plant Protein on Glycemic Control in Diabetes: A Systematic Review and Meta-Analysis of Randomized Controlled Trials. 